\title{
Training family physicians in shared decision-making to reduce the overuse of antibiotics in acute respiratory infections: a cluster randomized trial
}

\author{
France Légaré MD PhD, Michel Labrecque MD PhD Michel Cauchon MD, Josette Castel MD MSc, \\ Stéphane Turcotte MSc, Jeremy Grimshaw MB ChB PhD
}

Competing interests: None declared.

This article has been peer reviewed.

Correspondance to:

France Légaré,

france.legare@mfa.ulaval.ca

CMAJ 2012. DOI:10.1503

/cmaj.120568

\begin{abstract}
Background: Few interventions have proven effective in reducing the overuse of antibiotics for acute respiratory infections. We evaluated the effect of DECISION+2, a shared decision-making training program, on the percentage of patients who decided to take antibiotics after consultation with a physician or resident.
\end{abstract}

Methods: We performed a randomized trial, clustered at the level of family practice teaching unit, with 2 study arms: DECISION+2 and control. The DECISION+2 training program included a 2-hour online tutorial followed by a 2-hour interactive seminar about shared decision-making. The primary outcome was the proportion of patients who decided to use antibiotics immediately after consultation. We also recorded patients' perception that shared decision-making had occurred. Two weeks after the initial consultation, we assessed patients' adherence to the decision, repeat consultation, decisional regret and quality of life.
Results: We compared outcomes among 181 patients who consulted 77 physicians in 5 family practice teaching units in the DECISION+2 group, and 178 patients who consulted 72 physicians in 4 family practice teaching units in the control group. The percentage of patients who decided to use antibiotics after consultation was $52.2 \%$ in the control group and $27.2 \%$ in the DECISION+2 group (absolute difference $25.0 \%$, adjusted relative risk $0.48,95 \%$ confidence interval $0.34-0.68)$. DECISION+2 was associated with patients taking a more active role in decision-making $(Z=3.9, p<0.001)$. Patient outcomes 2 weeks after consultation were similar in both groups.

Interpretation: The shared decision-making program DECISION+2 enhanced patient participation in decision-making and led to fewer patients deciding to use antibiotics for acute respiratory infections. This reduction did not have a negative effect on patient outcomes 2 weeks after consultation.

ClinicalTrials.gov trial register no. NCT01116076.
$\mathrm{D}$ espite recent efforts to decrease the use of antibiotics for acute respiratory infections, their prescription is still too frequent ${ }^{1,2}$ and may be contributing to antibiotic resistance. ${ }^{1}$ Only $6 \%-18 \%$ of children with acute respiratory infections, $5 \%-15 \%$ of adults with pharyngitis and $38 \%$ of adults with acute rhinosinusitis have bacterial infections. ${ }^{3.4}$ Studies investigating improvement in clinical decision-making about the use of antibiotics for acute respiratory infections have been inconclusive, and interventions to reduce their use have shown only moderate success. ${ }^{5}$ In the shared decision-making model, a health care professional and the patient make a decision together based on the best available evidence and the patient's values and preferences. ${ }^{6}$ Shared decision-making is recognized as an effective strategy for reducing the overuse of treatment options not clearly associated with benefits for all patients.
In a randomized pilot trial, we showed that an earlier version of the training program in shared decision-making (DECISION+) reduced the proportion of patients who decided to use antibiotics immediately after consulting for acute respiratory infections (control 49\%, DECISION+ 33\%; absolute difference 16\%; $p=$ 0.08 ), a reduction that was maintained 6 months later. ${ }^{8}$ However, because only $46 \%$ of enrolled providers in the pilot trial participated in all three 3-hour workshops, we improved the training program before conducting a definitive trial. ${ }^{9}$ Following an in-depth evaluation with participants in the pilot trial, ${ }^{10,11}$ we modified the training program and renamed it DECISION+2. In the current study, we evaluated its effect on the proportion of patients who decided to use antibiotics for acute respiratory infections after physician consultation. 


\section{Methods}

The results from our pilot trial (NCT00354315) and protocol for this trial (NCT01116076) have been published. ${ }^{8-12}$ The current study was a multicentre, parallel cluster randomized trial conducted in a network of the 12 family practice teaching units (unit of randomization) affiliated with the Department of Family Medicine and Emergency Medicine at Université Laval in 6 regions of Quebec. The trial had 2 arms and was conducted in 3 phases (Figure 1): baseline data collection (family physician and patient recruitment, July through October 2010); intervention
(DECISION+2, November 2010); and postintervention data collection (patient recruitment, November 2010 through April 2011).

The Institutional Review Boards of the Centre de Santé et des Services Sociaux de la VieilleCapitale, the Hôpital régional du Centre de Santé et des Services Sociaux de Rimouski-Neigette and the Centre Hospitalier Régional de Lanaudière approved this study.

\section{Participants}

We approached all family physicians, including physician teachers and residents, who provided care in the walk-in clinics of the 12 family practice

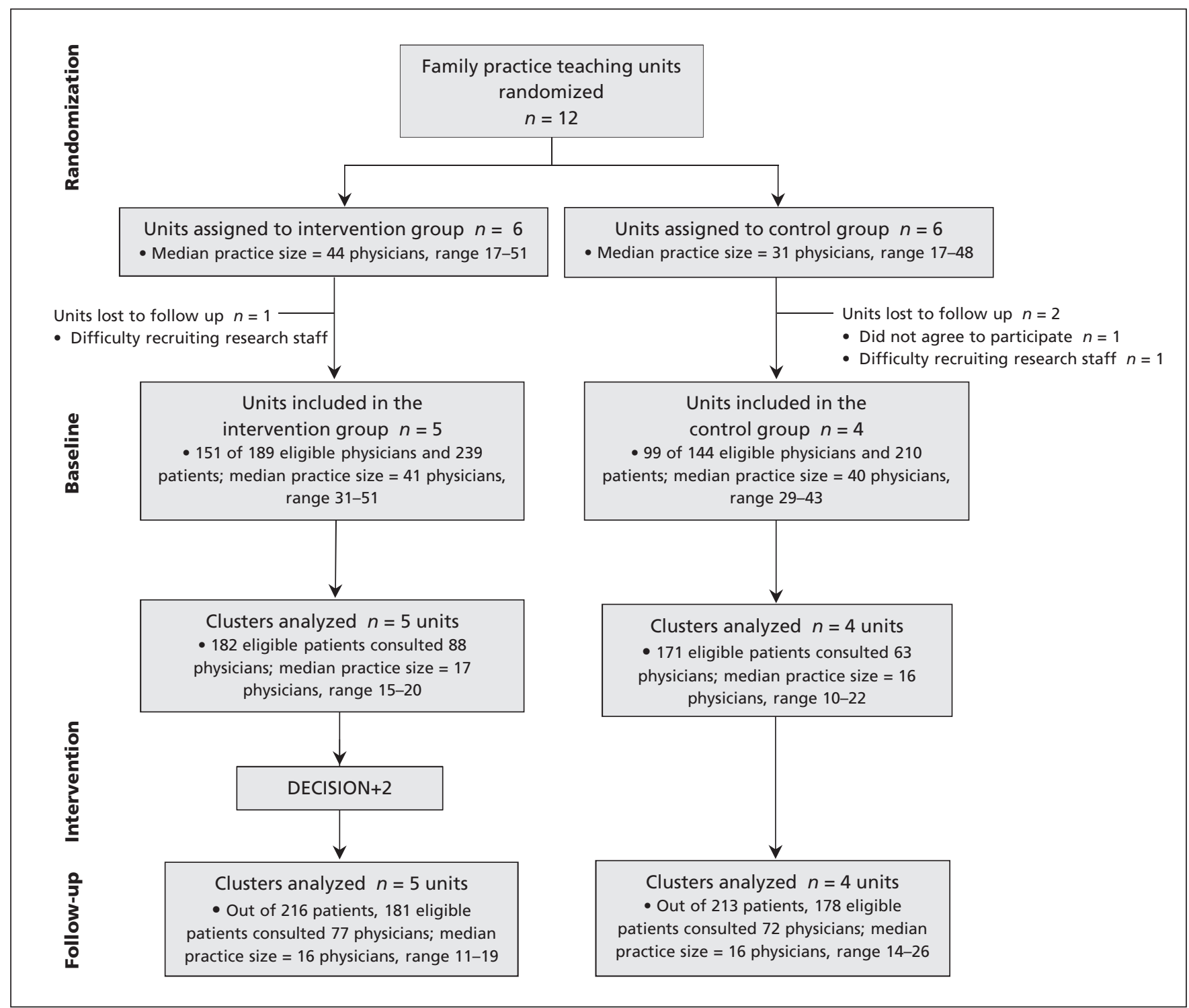

Figure 1: Flow diagram of the DECISION+2 trial. In the DECISION+2 group, 11 of the 189 eligible physicians who were not available during the first phase of patient recruitment were recruited (completed the baseline questionnaire) after DECISION+2 training began and therefore were not included in the final analysis. Out of $162(151+11), 103$ completed both the online tutorial and the interactive workshop, 16 completed only the interactive workshop, 15 completed only the online tutorial, and 28 completed none of the training components. Thus, $72.8 \%(118 / 162)$ completed the online tutorial, and $73.5 \%(119 / 162)$ completed the interactive workshop. In the control group, 9 of the 144 eligible physicians who were not available during the first phase of patient recruitment were recruited (completed the baseline questionnaire) after DECISION+2 training began; these physicians were included in the follow-up. 
teaching units. We excluded physicians who had participated in the DECISION+ pilot trial ${ }^{13}$ or who did not expect to practise in the teaching unit during the trial period. In total, 162 family physicians participated in some or all of the training components. To reduce the risk of bias, patients with symptoms suggestive of an acute respiratory infection were initially recruited by a research assistant in the waiting room before consultation with a physician. We finally included patients (adults and children who were accompanied by a parent or legal guardian) with a diagnosis of acute respiratory infection (e.g., bronchitis, otitis media, pharyngitis or rhinosinusitis) and for which the use of antibiotics was subsequently considered either

\section{Box 1: DECISION+2 shared decision-making training program}

\section{Online self-tutorial}

- Module 1: Introduction

- introduce the shared decision-making process and acute respiratory infections

- Module 2: Diagnostic probabilities

- know the most useful signs and symptoms for the diagnosis of acute respiratory infections

- integrate notions of diagnostic probabilities

- know how to use diagnostic tools

- Module 3: Treatment

- know evidence on the effects of antibiotics in treating acute respiratory infections

- integrate the concepts of probability associated with the effects of antibiotics in treating acute respiratory infections

- if the option for antibiotics is selected, choose which one

- Module 4: Effective communication of risk and benefits

- understand the essential elements of effective communication of treatment options and their benefits and risks

- use the communication tool on the benefits and risks associated with the use or not of antibiotics to treat acute respiratory infections

- Module 5: Promoting active patient participation

- ask questions relating to patient preferences and values, such as questions regarding their concerns about the benefits and risks associated with taking an antibiotic or not

- use a visual tool to help patients clarify their values and preferences about the benefits and risks associated with taking an antibiotic or not verify patient comfort with the decision made

\section{Interactive workshop}

- estimate the diagnostic probabilities for acute respiratory infections

- describe therapeutic options available for treating acute respiratory infections and describe their risks and benefits

- use effective communication strategies to share risks and benefits of the options regarding use of antibiotics to treat acute respiratory infections

- identify the patients' values and preferences, consider their opinions and involve them in the decision to use or not to use an antibiotic to treat acute respiratory infections

- use decision support tools that promote shared decision-making

Decision support tool

- available in the consultation office (Appendix 1, available at www.cmaj .ca/lookup/suppl/doi:10.1503/cmaj.120568/-/DC1) by the patient or physician during the visit. The patient, parent or legal guardian had to be able to read, understand and write French. Informed consent was obtained.

\section{Randomization}

A biostatistician used Internet-based software to simultaneously randomize all 12 family practice teaching units to either the intervention group (DECISION+2) or control group. The teaching units were stratified according to rural or urban location.

\section{Intervention}

DECISION+2 consisted of a 2-hour online tutorial followed by a 2-hour on-site interactive workshop (Box 1). The online tutorial addressed key components of the clinical decision-making process about antibiotic treatment for acute respiratory infections in primary care. Participants (teachers and residents) had one month to complete the online tutorial.

Facilitators who were trained during the DECISION+ pilot trial were updated on DECI$\mathrm{SION}+2$. These facilitators led the on-site interactive workshop, which aimed to help physicians review and integrate the concepts they acquired during the online training. Both the online tutorial and workshop included videos, exercises and decision aids to help physicians communicate to their patients the probability of a bacterial acute respiratory infection and the benefits and harms associated with the use of antibiotics (Appendix 1, available at www.cmaj.ca/lookup/suppl/doi:10 .1503/cmaj.120568/-/DC1). As part of the intervention, research assistants verified that the decision aids were available in each of the walk-in consultation rooms in all of the family practice teaching units in the intervention arm.

\section{Control}

Physicians in the control group were asked to provide usual care. To avoid contamination bias, access to the online tutorial was denied to participants in the control group during the trial.

\section{Outcomes}

The primary outcome was the proportion of patients who decided to use antibiotics immediately after consultation. As soon as the consultation was finished, patients and physicians independently completed self-administered questionnaires, which solicited information about the diagnosis, whether the use of antibiotics was discussed, and the decision about the use of antibiotics after the consultation (delayed antibiotic use, no antibiotic use or immediate antibiotic use).

At this time, we also collected data about 
3 secondary outcomes for both physicians and patients. We used the Decisional Conflict Scale to assess decisional conflict, ${ }^{14}$ the modified Control Preference Scale to assess the perception that shared decision-making had occurred, ${ }^{15-17}$ and a single-question Likert scale to assess the quality of the decision made. Two weeks later, we measured 5 additional secondary outcomes, at which time a research assistant telephoned patients to assess adherence to the decision (a single item asking if the patient maintained the decision made), repeat consultation (a single item asking if the patient had a repeat consult for the same reason), decisional regret (Decisional Regret Scale), ${ }^{18}$ quality of life (SF-12), ${ }^{19}$ and intention to engage in shared decision-making in future consultations regarding the use of antibiotics for acute respiratory infections (questions based on the Theory of Planned Behaviour) ${ }^{20}$

Family physicians' intentions to engage in shared decision-making and their intentions to adhere to clinical practice guidelines in this context were recorded at baseline and again at the end of the study. Sociodemographic information, includ- ing preferred role in decision-making (Control Preference Scale), ${ }_{1}^{17}$ was recorded at trial entry for physicians and before consultation for patients.

\section{Sample size calculation}

Our sample size estimate was based on our pilot study. ${ }^{8}$ We assumed that the minimum clinical significance for an absolute reduction of the proportion of patients who decided to use antibiotics immediately after consultation was $20 \%$. To detect a possible reduction from $60 \%$ to $40 \%$ with $80 \%$ power at a $5 \%$ significance level with the intracluster correlation coefficient of 0.02 estimated from our pilot trial, we needed 288 patients (or 24 in each of the 12 family practice teaching units). To compensate for loss to follow-up, we fixed the maximum recruitment of patients at 350 for each data collection period (175 patients per group).

\section{Statistical analysis}

Statistical analysis was performed by a statistician who was unaware of the teaching unit allocations. For the primary outcome, we combined delayed antibiotic use and no antibiotic use into a single

Table 1: Characteristics of patients in the family practice teaching units before and after the intervention*

\begin{tabular}{|c|c|c|c|c|}
\hline \multirow[b]{3}{*}{ Characteristic§ } & \multicolumn{4}{|c|}{$\%(n / N)$ of patients $\dagger$} \\
\hline & \multicolumn{2}{|c|}{ Before intervention } & \multicolumn{2}{|c|}{ After intervention } \\
\hline & $\begin{array}{l}\text { Intervention units } \\
\qquad n=5\end{array}$ & $\begin{array}{c}\text { Control units } \\
\quad n=4\end{array}$ & $\begin{array}{l}\text { Intervention units } \\
\qquad n=5\end{array}$ & $\begin{array}{c}\text { Control units } \\
n=4\end{array}$ \\
\hline Female & $65.6(118 / 180)$ & $59.8(101 / 169)$ & $64.6(117 / 181)$ & $68.0(121 / 178)$ \\
\hline Adults $\ddagger$ & $64.3(117 / 182)$ & $77.8(133 / 171)$ & $60.9(109 / 179)$ & $83.6(148 / 177)$ \\
\hline Children & $36.1 \quad(65 / 180)$ & $22.2(38 / 171)$ & $39.1 \quad(70 / 179)$ & $16.4 \quad(29 / 177)$ \\
\hline \multicolumn{5}{|l|}{ Age, yr, mean \pm SD } \\
\hline Adults & $39.3 \pm 12.4$ & $43.3 \pm 16.2$ & $40.8 \pm 15.1$ & $43.3 \pm 14.8$ \\
\hline Children & $4.6 \pm 3.8$ & $5.0 \pm 3.9$ & $4.9 \pm 3.7$ & $4.9 \pm 4.1$ \\
\hline Household size, mean \pm SD & $3.5 \pm 1.1$ & $3.3 \pm 1.3$ & $3.4 \pm 1.1$ & $3.2 \pm 1.1$ \\
\hline$\geq 1$ chronic disease & $14.8(27 / 182)$ & $17.5(30 / 171)$ & $8.8 \quad(16 / 181)$ & $15.7(28 / 178)$ \\
\hline College or university degree & $59.0 \quad(69 / 117)$ & $60.2(80 / 133)$ & $58.0 \quad(65 / 112)$ & $63.1 \quad(94 / 149)$ \\
\hline Private drug insurance & $68.1(79 / 116)$ & $71.8 \quad(94 / 131)$ & $75.9 \quad(85 / 112)$ & $67.8(101 / 149)$ \\
\hline \multicolumn{5}{|l|}{ Preferred role in decision-making } \\
\hline Patient decides & $1.2 \quad(2 / 171)$ & $5.4 \quad(9 / 166)$ & $3.7 \quad(6 / 163)$ & $1.2 \quad(2 / 165)$ \\
\hline $\begin{array}{l}\text { Patient decides after considering } \\
\text { physician's opinion }\end{array}$ & $29.8 \quad(51 / 171)$ & $22.9(38 / 166)$ & $28.2(46 / 163)$ & $33.3(55 / 165)$ \\
\hline Parties decide together & $21.1 \quad(36 / 171)$ & $29.5(49 / 166)$ & $32.5(53 / 163)$ & $26.1(43 / 165)$ \\
\hline $\begin{array}{l}\text { Physician decides after considering } \\
\text { patient's opinion }\end{array}$ & $38.0(65 / 171)$ & $36.1 \quad(60 / 166)$ & $30.1 \quad(49 / 163)$ & $32.1 \quad(53 / 165)$ \\
\hline Physician decides & $9.9(17 / 171)$ & $6.0 \quad(10 / 166)$ & $5.5 \quad(9 / 163)$ & $7.3 \quad(12 / 165)$ \\
\hline \multicolumn{5}{|c|}{$\begin{array}{l}\text { Note: } \mathrm{SD}=\text { standard deviation. } \\
\text { *The intervention was } \mathrm{DECISION}+2 \text {, a training program in shared decision-making designed to reduce the proportion of patients deciding to use antibiotics } \\
\text { immediately after consulting their physician because of an acute respiratory infection. } \\
\text { tUnless stated otherwise. } \\
\text { fAge } \geq 18 \text { years. } \\
\text { §Because of missing values, the denominator for some characteristics may have differed from the sample size. }\end{array}$} \\
\hline
\end{tabular}


category and contrasted it with immediate antibiotic use, because only a small percentage of patients who delay using antibiotics fill their prescription..$^{21}$ Results are reported at the level of the individual patient, and we used the generalized linear mixed model procedure to perform the analyses. We adjusted where appropriate for potentially confounding variables, baseline scores and clustering of patients at the level of the teaching unit. The association between the role patients perceived that they had played in decision-making during consultation and their decision to use antibiotics immediately after the consultation was evaluated by use of the Cochran-Armitage trend test.

\section{Results}

In the DECISION+2 group, 11 of the 189 eligible physicians who were not available during the first phase of patient recruitment were recruited (completed the baseline questionnaire) after DECI$\mathrm{SION}+2$ training began and therefore were not included in the final analysis. Out of $162(151+$ 11), 103 completed both the online tutorial and the interactive workshop, 16 completed only the interactive workshop, 15 completed only the online tutorial, and 28 completed none of the training components. Thus, $72.8 \%(118 / 162)$ completed the online tutorial, and $73.5 \%$ (119/162) completed the interactive workshop. In the control group, 9 of the 144 eligible physicians who were not available during the first phase of patient recruitment were recruited (completed the baseline questionnaire) after DECISION+2 training began; these physicians were included in the follow-up.

In total, 9 of the 12 randomized family practice teaching units participated in the study (Figure 1). In general, key characteristics of the patients (Table 1) and family practice teaching units and physicians (Table 2) in the DECISION+2 group were similar to those in the control group. However, during the postintervention data collection phase, there were more children, fewer patients with chronic diseases, and more patients with private insurance in the intervention than in the control group (Table 1). Only age group (children or adults) was associated with the decision to use antibiotics.

Although the percentage of patients who decided to use antibiotics immediately after consultation was similar at baseline, after the intervention patients in the DECISION+2 group were significantly less likely than patients in the control group to report a decision to use antibiotics imme-

Table 2: Characteristics of physicians in the family practice teaching units before and after the intervention

\begin{tabular}{|c|c|c|c|c|}
\hline \multirow[b]{3}{*}{ Characteristict } & \multicolumn{4}{|c|}{$\%(n / N)$ of physicians* } \\
\hline & \multicolumn{2}{|c|}{ Before intervention } & \multicolumn{2}{|c|}{ After intervention } \\
\hline & $\begin{array}{l}\text { Intervention units } \\
\qquad n=5\end{array}$ & $\begin{array}{l}\text { Control units } \\
\quad n=4\end{array}$ & $\begin{array}{l}\text { Intervention units } \\
\qquad n=5\end{array}$ & $\begin{array}{c}\text { Control units } \\
n=4\end{array}$ \\
\hline Teachers & $51.0(77 / 151)$ & $51.5(51 / 99)$ & $48.1(78 / 162)$ & $49.1(53 / 108)$ \\
\hline Female & $62.3(48 / 77)$ & $68.6(35 / 51)$ & $62.8(49 / 78)$ & $67.9(36 / 53)$ \\
\hline Age, yr, mean \pm SD & $40.5 \pm 14.9$ & $44.0 \pm 10.0$ & $42.0 \pm 9.4$ & $43.7 \pm 10.0$ \\
\hline Professional experience, yr, mean \pm SD & $13.7 \pm 10.1$ & $15.6 \pm 10.7$ & $13.9 \pm 10.3$ & $15.2 \pm 10.7$ \\
\hline Residents & $49.0(74 / 151)$ & $48.5(48 / 99)$ & $51.2(84 / 162)$ & $50.9(55 / 108)$ \\
\hline Female & $70.2(52 / 74)$ & $64.6(31 / 48)$ & $72.3(60 / 84)$ & $61.8(34 / 55)$ \\
\hline Age, $y r$, mean $\pm S D$ & $28.1 \pm 4.7$ & $27.3 \pm 4.2$ & $27.9 \pm 4.5$ & $27.3 \pm 4.1$ \\
\hline Resident 1 & $52.7(39 / 74)$ & $58.3(28 / 48)$ & $55.4(47 / 84)$ & $52.7(29 / 55)$ \\
\hline Resident 2 & $47.3(35 / 74)$ & $41.7(20 / 48)$ & $44.6(37 / 84)$ & $47.3(26 / 55)$ \\
\hline \multicolumn{5}{|l|}{ Preferred role in decision-making } \\
\hline Patient decides & $10.1(15 / 149)$ & $8.1(8 / 99)$ & $10.0(16 / 160)$ & $8.3(9 / 108)$ \\
\hline $\begin{array}{l}\text { Patient decides after considering physician's } \\
\text { opinion }\end{array}$ & $19.5(29 / 149)$ & $14.1(14 / 99)$ & $21.9(35 / 160)$ & $14.8(16 / 108)$ \\
\hline Parties decide together & $50.3(75 / 149)$ & $47.5(47 / 99)$ & $48.8(78 / 160)$ & $46.3(50 / 108)$ \\
\hline $\begin{array}{l}\text { Physician decides after considering patient's } \\
\text { opinion }\end{array}$ & $20.1(30 / 149)$ & $30.3(30 / 99)$ & $19.4(31 / 160)$ & $30.6(33 / 108)$ \\
\hline Physician decides & $-(0 / 149)$ & $-(0 / 99)$ & $-(0 / 160)$ & $-(0 / 108)$ \\
\hline
\end{tabular}


diately after consultation (Table 3 ). The reduction in decisions to use antibiotics was observed in all intervention teaching units, while an increase was seen in 3 of 4 teaching units in the control group. The level of agreement was high between physicians and patients $(\kappa=0.96)$ concerning the decision about immediate versus delayed or no antibiotics use after the initial consultation.

Figure 2 shows the effect DECISION+2 had on the role patients perceived that they had played in decision-making during consultation. Among patients who consulted after the intervention, a higher proportion of patients in the DECISION+2 group (67\%) than in the control group (49\%) reported having an active role in the decision-making process. This difference was larger among patients who consulted teachers than among those who consulted residents. There was no significant difference between the study groups at baseline.

There was no difference between trial groups with regard to the other secondary outcomes (Table 4). The slight effect observed on patient decisional regret was not clinically significant considering the low effect size observed (0.29).

\section{Interpretation}

We found that DECISION+2 significantly reduced decisions to use antibiotics for acute respiratory infections. This reduction was associated with enhanced patient participation in decisionmaking. The training had no statistically significant effect on decisional conflict, perception of the quality of the decision among family physicians and patients, decisional regret, repeat consultation or patient quality of life 2 weeks later.

Our data suggest that it is possible to train physicians to engage patients actively in decision-making. ${ }^{22-24}$ In the context of acute respiratory infections, this appears to reduce the use of a treatment option (i.e., antibiotics) not clearly associated with benefits for all patients.

The equally high pre- and postintervention intention to integrate shared decision-making into practice among both groups may be partly explained by a desirability bias. Although the results of our trial cannot fully inform policymakers as to which components of DECISION+2 are the "active ingredients," taken overall, it is effective. This program could be used in emergency

Table 3: Proportion of patients deciding to use antibiotics immediately after consulting with their physician before and after the intervention, by study group, family practice teaching unit, type of physician and patient age group

\begin{tabular}{|c|c|c|c|c|c|c|}
\hline \multirow[b]{3}{*}{ Variable } & \multicolumn{4}{|c|}{$\begin{array}{l}\% \text { of patients deciding to use antibiotics } \\
\text { immediately after consultation }\end{array}$} & \multirow[b]{3}{*}{$\begin{array}{l}\text { Absolute } \\
\text { difference }\end{array}$} & \multirow[b]{3}{*}{$\begin{array}{l}\text { Adjusted relative } \\
\text { risk* }(95 \% \mathrm{Cl})\end{array}$} \\
\hline & \multicolumn{2}{|c|}{ At baseline } & \multicolumn{2}{|c|}{ After intervention } & & \\
\hline & $\begin{array}{l}\text { Intervention } \\
\text { units } \\
n=5\end{array}$ & $\begin{array}{l}\text { Control } \\
\text { units } \\
n=4\end{array}$ & $\begin{array}{l}\text { Intervention } \\
\text { units } \\
n=5\end{array}$ & $\begin{array}{l}\text { Control } \\
\text { units } \\
n=4\end{array}$ & & \\
\hline \multicolumn{7}{|l|}{ Teaching unit } \\
\hline All units & 41.2 & 39.2 & 27.2 & 52.2 & 25.0 & $0.5(0.3$ to 0.7$)$ \\
\hline Unit 1 & 38.7 & - & 26.3 & - & - & - \\
\hline Unit 2 & 48.7 & - & 31.0 & - & - & - \\
\hline Unit 3 & 43.9 & - & 25.7 & - & - & - \\
\hline Unit 4 & 40.5 & - & 25.5 & - & - & - \\
\hline Unit 5 & 32.4 & - & 29.6 & - & - & - \\
\hline Unit 6 & - & 54.5 & - & 73.7 & - & - \\
\hline Unit 7 & - & 44.4 & - & 51.0 & - & - \\
\hline Unit 8 & - & 22.6 & - & 49.0 & - & - \\
\hline Unit 9 & - & 44.4 & - & 38.1 & - & - \\
\hline Type of physician & & & & & & - \\
\hline Resident & 37.5 & 44.4 & 28.6 & 46.7 & 18.1 & $0.6(0.4$ to 0.9$)$ \\
\hline Teacher & 44.1 & 36.8 & 25.7 & 56.3 & 30.6 & 0.5 (.3 to 0.7$)$ \\
\hline \multicolumn{7}{|l|}{ Patient age group } \\
\hline Adults & 41.9 & 39.8 & 26.6 & 50.7 & 24.1 & 0.5 (0.4 to 0.8$)$ \\
\hline Children & 40.0 & 36.8 & 27.1 & 65.5 & 38.4 & 0.4 (0.3 to 0.7$)$ \\
\hline
\end{tabular}




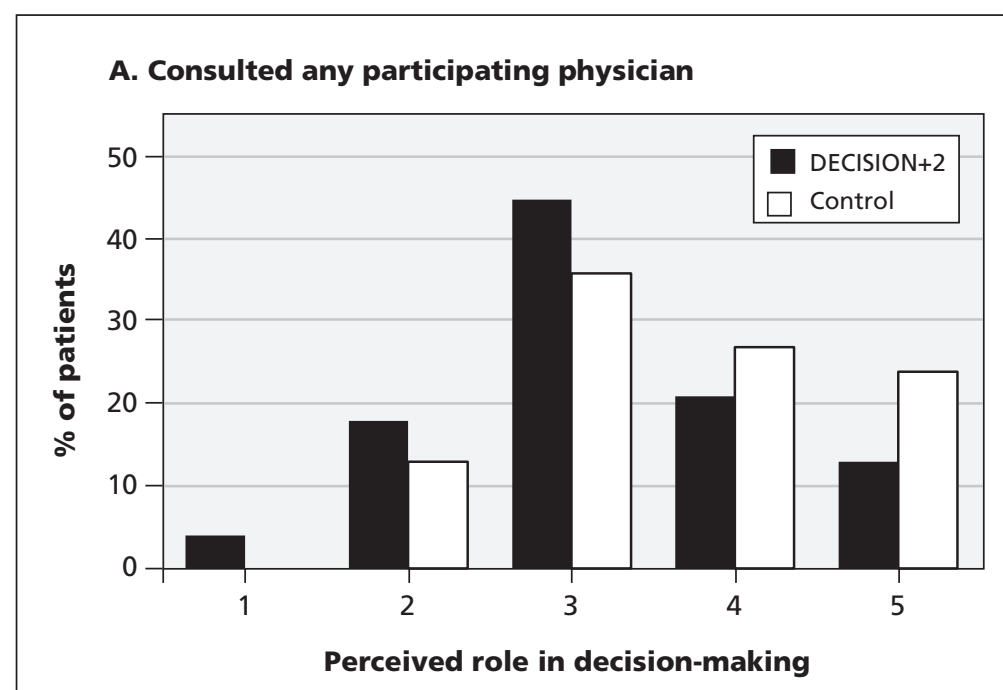

\section{B. Consulted a teaching physician}

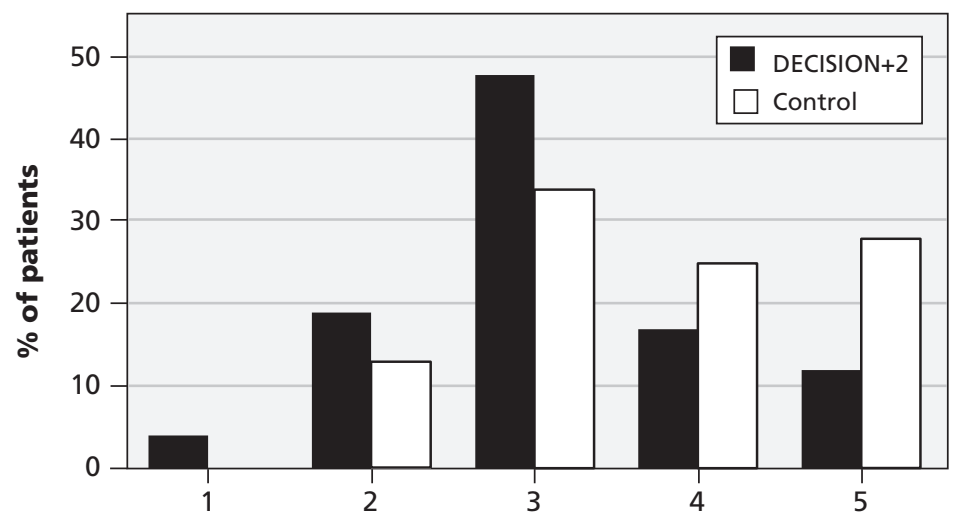

Perceived role in decision-making

\section{Consulted a resident}

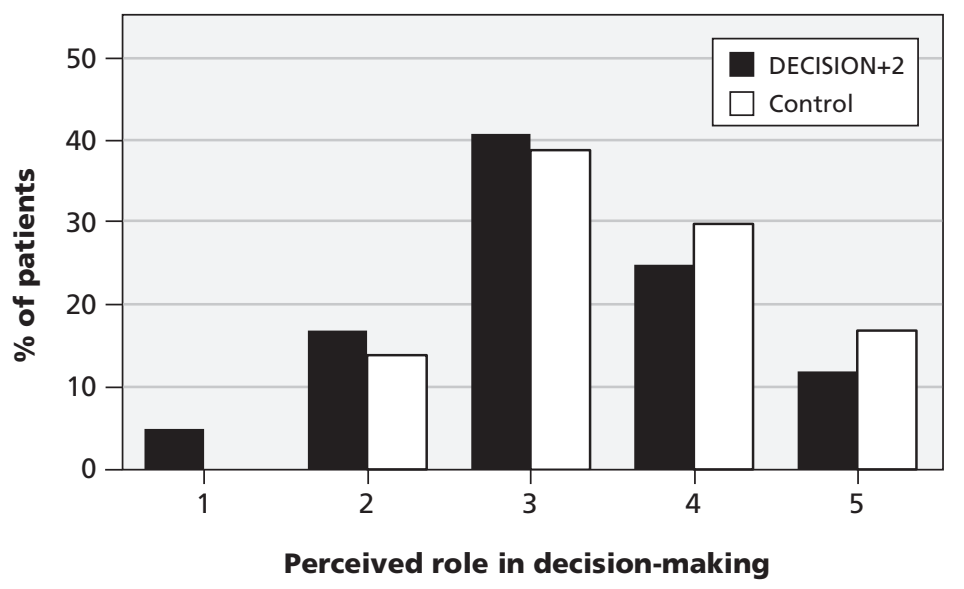

Figure 2: Patient perceptions of how much they participated in decision-making during consultation with $A)$ any participating physician $(Z=3.9 ; p<0.001), B)$ a teaching physician $(Z=3.7 ; p<0.001)$ or $C)$ a resident $(Z=-4.7918 ; p=0.03)$. The perceptions were grouped as follows 1 ) I made the decision alone; 2) I made the decision but considered the opinion of my doctor; 3) My doctor and I decided equally; 4) My doctor made the decision but considered my opinion; 5) My physician made the decision alone. departments or to train nurses in helping patients make informed value-based decisions before visiting a physician or emergency department.

Our results are consistent with those from a previous study in which the use of an interactive booklet about childhood respiratory tract infections in primary care consultations led to a significant reduction in antibiotic prescribing. ${ }^{25}$ In another recent study, a combination of online educational modules and a seminar on motivational interviewing led to a reduction in dispensing of oral antibiotics with no significant change in admissions to hospital, repeat consultations or costs. ${ }^{26}$ These studies indicate that a combination of live and media education are generally effective in changing physician performance in the context of antibiotic use for acute respiratory infections. ${ }^{27}$ These findings are important given the debate and widespread skepticism about the effect of medical education on the performance of physicians in the practice setting. ${ }^{28,29}$

Our results are consistent with those of our pilot trial. Although our pilot trial involved 5 large private practices with no residents, the baseline percentage of patients who decided to use antibiotics immediately after consultation was $56 \%$ in the intervention group and $54 \%$ in the control group. In contrast, in our current study the baseline percentage of patients who decided to use antibiotics immediately after consultation was $41 \%$ in the intervention group and $39 \%$ in the control group. Although one could argue that medical practices differ between private clinics and family practice teaching units, ${ }^{30}$ we believe that the difference in outcomes observed at baseline can be attributed to a seasonal effect (baseline recruitment in late fall and winter in the pilot study v. summer and early fall in the current trial); this has been observed in other studies. ${ }^{31}$ The seasonal effect might also explain the $13 \%$ increase in prescriptions in the control group between baseline (recruitment in the summer) and after the intervention (recruitment in the winter).

\section{Limitations}

Our trial had several limitations. First, 3 of the initial 12 clusters were lost to follow-up. DECISION+2 was integrated into the official residency training program, and all teaching units in the invention group received it simultaneously. However, because the program calendar was finalized in May, we had to perform randomization before meeting with the invitees in July and receiving their formal acceptance to participate. We believe that the impact of this limitation was minimal because loss was balanced between experimental and control groups and the characteristics of the participating units were similar. 
Second, we did not report an objective measure of antibiotic use by patients, such as antibiotics dispensed, because it was impossible in this clinical context. However, the decision to use antibiotics reported independently by physicians and patients showed a high degree of agreement. In addition, a high level of adherence to the decision was reported by the patients.

Third, because this was a pragmatic trial, we did not control for other potential variables external to the residency program (e.g., whether participating physicians had taken other training programs on antibiotic prescribing or read material about acute respiratory infections beyond their residency requirements).

Fourth, we collected data from patients who had consulted with a participating physician but not from all patients who consulted a physician at the walk-in clinics of the participating family practice teaching units, so we do not know if the impact of DECISION+2 would have been similar on physicians who did not enrol in this trial but who were still exposed to the training program.

Fifth, although the biostatistician was unaware of group allocation, the researchers and research assistants who recruited patients and collected data were not.

\section{Conclusion}

By enhancing patient participation in decisionmaking, the DECISION+2 training program reduced the proportion of patients who decided to use antibiotics for acute respiratory infections immediately after consultation. This reduction occurred with no negative effect on patient outcomes at 2 weeks. Future studies should assess

Table 4: Secondary outcome measures before and after the intervention

\begin{tabular}{|c|c|c|c|c|c|c|}
\hline \multirow[b]{3}{*}{ Outcome measure } & \multicolumn{4}{|c|}{ Mean \pm SD or $\%$ (range) } & \multirow[b]{3}{*}{$\begin{array}{l}\text { Absolute } \\
\text { difference }\end{array}$} & \multirow[b]{3}{*}{$\begin{array}{c}\text { Adjusted RR or MD* } \\
(95 \% \mathrm{Cl})\end{array}$} \\
\hline & \multicolumn{2}{|c|}{ Before intervention } & \multicolumn{2}{|c|}{ After intervention } & & \\
\hline & $\begin{array}{l}\text { Intervention } \\
\text { units } \\
n=5\end{array}$ & $\begin{array}{l}\text { Control } \\
\text { units } \\
n=4\end{array}$ & $\begin{array}{l}\text { Intervention } \\
\text { units } \\
n=5\end{array}$ & $\begin{array}{l}\text { Control } \\
\text { units } \\
n=4\end{array}$ & & \\
\hline Patients & \multicolumn{4}{|c|}{ Immediately after consultation } & & \\
\hline Decisional conflict $†$ & $5.1(0$ to 13.5$)$ & 4.2 (0 to 8.9$)$ & 4.6 (2.6 to 7.4$)$ & $6.3(0$ to 12.8$)$ & 1.7 & RR 0.8 (0.2 to 2.4 ) \\
\hline \multirow[t]{2}{*}{ Quality of decision§ } & $8.7 \pm 1.5$ & $8.7 \pm 1.5$ & $8.5 \pm 1.6$ & $8.5 \pm 1.5$ & 0.0 & MD $0.0(-0.4$ to 0.4$)$ \\
\hline & \multicolumn{4}{|c|}{2 wk after consultation } & & \\
\hline \multicolumn{7}{|l|}{ Quality of lifeł } \\
\hline Physical scale & $49.3 \pm 8.8$ & $47.7 \pm 8.9$ & $49.4 \pm 7.5$ & $48.2 \pm 7.8$ & 1.2 & MD 0.4 (-2.6 to 3.3$)$ \\
\hline Mental scale & $51.2 \pm 8.0$ & $48.5 \pm 11.0$ & $50.8 \pm 9.3$ & $51.2 \pm 8.4$ & 0.4 & $\mathrm{MD}-1.9(-4.9$ to 1.1$)$ \\
\hline $\begin{array}{l}\text { Intention to engage in } \\
\text { shared decision-makingף }\end{array}$ & $1.9 \pm 1.2$ & $2.0 \pm 1.2$ & $2.1 \pm 1.1$ & $1.9 \pm 1.2$ & 0.2 & MD $0.2(-0.1$ to 0.4$)$ \\
\hline Adherence to decision & $\begin{array}{c}91.6 \\
\text { (88.9 to } 94.6)\end{array}$ & $\begin{array}{c}88.4 \\
\text { (84.1 to } 93.2)\end{array}$ & $\begin{array}{c}87.7 \\
\text { (86.2 to } 88.5)\end{array}$ & $\begin{array}{c}91.5 \\
\text { (84.8 to } 100)\end{array}$ & 3.8 & RR 1.0 (0.9 to 1.0$)$ \\
\hline $\begin{array}{l}\text { Repeat consultation } \\
\text { for the same reason }\end{array}$ & $\begin{array}{c}21.6 \\
\text { (12.1 to } 29.7)\end{array}$ & $\begin{array}{c}13.4 \\
(9.9 \text { to } 15.9)\end{array}$ & $\begin{array}{c}22.7 \\
(10.3 \text { to } 27.3)\end{array}$ & $\begin{array}{c}15.2 \\
(11.9 \text { to } 19.4)\end{array}$ & 7.5 & RR 1.3 (0.7 to 2.3 ) \\
\hline Regret over decision** & $10.5 \pm 15.4$ & $10.8 \pm 20.8$ & $12.4 \pm 19.1$ & $7.6 \pm 13.7$ & 4.8 & MD 4.8 (0.9 to 8.7$)$ \\
\hline Physicians & \multicolumn{4}{|c|}{ Immediately after consultation } & & \\
\hline Decisional conflict† & 4.5 (0 to 9.0$)$ & $3.0(0$ to 5.9$)$ & $4.6(0$ to 6.1$)$ & 1.1 (0 to 2.4 ) & 3.5 & RR 3.4 (0.3 to 38.0 ) \\
\hline \multirow[t]{2}{*}{ Quality of decision§ } & $8.2 \pm 1.1$ & $8.2 \pm 1.4$ & $8.2 \pm 1.3$ & $8.4 \pm 1.0$ & 0.2 & $\mathrm{MD}-0.2(-0.6$ to 0.2$)$ \\
\hline & \multicolumn{2}{|c|}{ At study entrance } & \multicolumn{2}{|c|}{ At study exit } & & \\
\hline $\begin{array}{l}\text { Intention to engage in } \\
\text { shared decision-making }\end{array}$ & $1.6 \pm 0.8$ & $1.6 \pm 0.9$ & $1.7 \pm 0.9$ & $1.8 \pm 0.7$ & 0.1 & MD 0.0 (-0.3 to 0.2$)$ \\
\hline $\begin{array}{l}\text { Intention to follow clinical } \\
\text { practice guidelines }\end{array}$ & $2.2 \pm 0.6$ & $2.2 \pm 0.7$ & $2.0 \pm 0.7$ & $2.2 \pm 0.7$ & 0.2 & $\mathrm{MD}-0.2(-0.5$ to 0.1$)$ \\
\hline \multicolumn{7}{|c|}{$\begin{array}{l}\text { Note: } \mathrm{Cl}=\text { confidence interval, } \mathrm{MD}=\text { mean difference, } \mathrm{RR}=\text { relative risk, } \mathrm{SD}=\text { standard deviation. } \\
{ }^{*} \text { Adjusted for cluster design and baseline values. } \\
\text { †Proportion who had a value of } 2.5 \text { or more on the Decisional Conflict Scale }(1=\text { low decisional conflict, } 5=\text { very high decisional conflict). } \\
\S 0=\text { very low quality, } 10=\text { very high quality. } \\
\neq 0=\text { much worse, } 100=\text { much better. } \\
\text { IScored on a } 3 \text {-item scale. Scores are presented as a mean of the score obtained from the } 3 \text { items. }-3=\text { strongly disagree, } 3=\text { strongly agree. } \\
* * 0=\text { very low regret, } 100=\text { very high regret. }\end{array}$} \\
\hline
\end{tabular}


the effectiveness of shared decision-making in other clinical areas in which overuse is an issue and assess what is needed to scale up the uptake of DECISION +2 by other health care professional training programs.

\section{References}

1. Patrick DM, Hutchinson J. Antibiotic use and population ecology: How you can reduce your "resistance footprint." CMAJ 2009; 180:416-21.

2. Coco A, Vernacchio L, Horst M, et al. Management of acute otitis media after publication of the 2004 AAP and AAFP clinical practice guideline. Pediatrics 2010;125:214-20.

3. Alberta Clinical Practice Guideline Working Group. Guideline for the diagnosis and treatment of acute pharyngitis. Edmonton (AB): Alberta Clinical Practice Guidelines Program; 1999.

4. Agency for Healthcare Research and Quality (AHRQ). Update on acute bacterial rhinosinusitis. Rockville (MD): US Department of Health and Human Services; 2005.

5. Arnold SR, Straus SE. Interventions to improve antibiotic prescribing practices in ambulatory care. Cochrane Database Syst Rev 2005;(4):CD003539.

6. Charles C, Gafni A, Whelan T. Shared decision-making in the medical encounter: What does it mean? (or it takes at least two to tango). Soc Sci Med 1997;44:681-92.

7. Evans R, Edwards A, Brett J, et al. Reduction in uptake of PSA tests following decision aids: systematic review of current aids and their evaluations. Patient Educ Couns 2005;58:13-26.

8. Légaré F, Labrecque M, LeBlanc A, et al. Training family physicians in shared decision making for the use of antibiotics for acute respiratory infections: a pilot clustered randomized controlled trial. Health Expect 2011;14(Suppl 1):96-110.

9. LeBlanc A, Légaré $\mathrm{F}$, Labrecque $\mathrm{M}$, et al. Feasibility of a randomised trial of a continuing medical education program in shared decision-making on the use of antibiotics for acute respiratory infections in primary care: the DECISION+ pilot trial. Implement Sci 2011;6:5.

10. Allaire AS, Labrecque M, Giguere A, et al. Barriers and facilitators to the dissemination of DECISION+, a continuing medical education program for optimizing decisions about antibiotics for acute respiratory infections in primary care: a study protocol. Implement Sci 2011;6:3

11. Allaire AS, Labrecque M, Giguere A, et al. What motivates family physicians to participate in training programs in shared decision making? J Contin Educ Health Prof 2012;32:98-107.

12. Légaré $\mathrm{F}$, Labrecque $\mathrm{M}$, Godin $\mathrm{G}$, et al. Training family physicians and residents in family medicine in shared decision making to improve clinical decisions regarding the use of antibiotics for acute respiratory infections: protocol for a clustered randomized controlled trial. BMC Fam Pract 2011;12:3.

13. Légaré $\mathrm{F}$, Labrecque $\mathrm{M}$, LeBlanc A, et al. Does training family physicians in shared decision making promote optimal use of antibiotics for acute respiratory infections? Study protocol of a pilot clustered randomised controlled trial. BMC Fam Pract 2007;8:65.

14. O'Connor AM. Validation of a decisional conflict scale. Med Decis Making 1995:15:25-30.

15. Melbourne E, Roberts S, Durand MA, et al. Dyadic OPTION: measuring perceptions of shared decision-making in practice Patient Educ Couns 2011:83:55-7.

16. Melbourne E, Sinclair K, Durand MA, et al. Developing a dyadic OPTION scale to measure perceptions of shared decision making. Patient Educ Couns 2010;78:177-83.

17. Strull WM, Lo B, Charles G. Do patients want to participate in medical decision making? JAMA 1984;252:2990-4.

18. Brehaut JC, O'Connor AM, Wood TJ, et al. Validation of a decision regret scale. Med Decis Making 2003;23:281-92.

19. Ware J Jr, Kosinski M, Keller SD. A 12-Item Short-Form Health Survey: construction of scales and preliminary tests of reliability and validity. Med Care 1996;34:220-33.

20. Ajzen I. The theory of planned behavior. Organ Behav Hum Decis Process 1991;50:179-211.

21. Arroll B, Kenealy T, Kerse N. Do delayed prescriptions reduce antibiotic use in respiratory tract infections? A systematic review. Br J Gen Pract 2003;53:871-7.

22. Légaré $F$, Ratté $S$, Stacey D, et al. Interventions for improving the adoption of shared decision making by healthcare professionals. Cochrane Database Syst Rev 2010;(5):CD006732.

23. Légaré F, Turcotte S, Stacey D, et al. Patients' perceptions of sharing in decisions: a systematic review of interventions to enhance shared decision making in routine clinical practice. Patient 2012;5:1-19
24. Légaré F, Politi MC, Drolet R, et al. Training health professionals in shared decision-making: an international environmental scan. Patient Educ Couns 2012 Feb. 1 [Epub ahead of print].

25. Francis NA, Butler CC, Hood K, et al. Effect of using an interactive booklet about childhood respiratory tract infections in primary care consultations on reconsulting and antibiotic prescribing: a cluster randomised controlled trial. BMJ 2009;339: b2885.

26. Butler CC, Simpson SA, Dunstan F, et al. Effectiveness of multifaceted educational programme to reduce antibiotic dispensing in primary care: practice based randomised controlled trial. $B M J$ 2012;344:d8173.

27. Davis D, Galbraith R. Continuing medical education effect on practice performance: effectiveness of continuing medical education: American College of Chest Physicians Evidence-Based Educational Guidelines. Chest 2009;135(Suppl3):42S-8S.

28. Bordage G, Carlin B, Mazmanian PE. Continuing medical education effect on physician knowledge: effectiveness of continuing medical education: American College of Chest Physicians Evidence-Based Educational Guidelines. Chest 2009;135(Suppl3): 29S-36S.

29. Davis D, Bordage G, Moores LK, et al. The science of continuing medical education: terms, tools, and gaps: effectiveness of continuing medical education: American College of Chest Physicians Evidence-Based Educational Guidelines. Chest 2009;135(Suppl3):8S-16S

30. Contandriopoulos AP, Fournier MA, Dassa C, et al. Profils de pratique des médecins généralistes du Québec. Montréal (QC): Groupe de recherche interdisciplinaire en santé, Université de Montréal; 2001.

31. Paul IM, Maselli JH, Hersh AL, et al. Antibiotic prescribing during pediatric ambulatory care visits for asthma. Pediatrics 2011 127:1014-21.

Affiliations: From the Research Centre of the Centre Hospitalier Universitaire de Québec (Légaré, Labrecque, Turcotte); the Department of Family Medicine and Emergency Medicine (Légaré, Labrecque, Cauchon, Castel), Université Laval, Québec, Que; and the Ottawa Health Research Institute (Grimshaw), Ottawa, Ont.

Contributors: France Légaré, Michel Labrecque and Jeremy Grimshaw conceived of and designed the study. Josette Castel and Michel Cauchon contributed to the design of the intervention and the acquisition of data. Stéphane Turcotte supervised data analysis. France Légaré and Michel Labrecque drafted the manuscript. All authors gave input regarding study concept and design, interpreted data, provided comments on drafts, revised the manuscript critically for important intellectual content and approved the final version of the manuscript submitted for publication.

Acknowledgements: The authors thank Gaston Godin, Annie LeBlanc and Claudine Laurier for providing comments on the research protocol and seeking funding. The authors thank the medical directors of the Family Practice Teaching Units affiliated with the Department of Family Medicine and Emergency Medicine at Université Laval for supporting the recruitment of physicians and residents. The authors thank Pierre Frémont, Kathleen Lemieux and Caroline Rhéaume for helping with the training sessions. The authors thank Isabelle Tremblay and the staff at the residency program directorship of the Department of Family Medicine and Emergency Medicine at Université Laval for providing expertise in the development of a 2-hour online tutorial. The authors thank Florence Doualla-Bell for providing helpful comments on an earlier draft of this manuscript. The authors thank Louisa Blair for assistance with manuscript preparation. France Légaré is Tier 2 Canada Research Chair is Implementation of Shared Decision-making in Primary Care. Jeremy Grimshaw is Tier 1 Canada Research Chair in Health Knowledge Transfer and Uptake.

Funding: This study was funded by a grant from the Conseil du médicament du Québec/Fonds de la recherche en santé du Québec. The funding organization had no role in the conception or design, conduct, analysis, interpretation or reporting of the study and no access to the data. None of the investigators received any financial compensation. 